\title{
HYBRID SOLAR - BIOMASS PLANTS FOR POWER GENERATION; TECHNICAL AND ECONOMIC ASSESSMENT
}

\section{J. SERVERT \\ G. SAN MIGUEL* \\ D. LÓPEZ}

Received: $24 / 02 / 10$

Accepted: 04/08/11
Universidad Politécnica de Madrid, E.T.S.I.I., Department of Energy Engineering and Fluidmechanics, c/ José Gutiérrez Abascal, 2, Madrid, 28006 (Spain)

*to whom all correspondence should be addressed: e-mail: g.sanmiguel@upm.es

\begin{abstract}
Environmental, economic and strategic reasons are behind the rapid impulse in the deployment of renewable energy sources that is taking place around the world. In addition to overcoming economic and commercial barriers, meeting the ambitious objectives set by most countries in this field will require the development of novel technologies capable of maximising the energy potential of different renewable sources at an acceptable cost. The use of solar radiation and biomass for power generation is growing rapidly, particularly in areas of the globe where these resources are plentiful, like Mediterranean countries. However, solar energy plants necessarily suffer from the intermittency of day/night cycles and also from reduced irradiation periods (winter, cloudy days, short transients). Biomass power plants have to confront the logistic problems associated with the continuous supply of very large amounts of a relatively scarce and seasonal fuel. Hybrid systems may provide the solution to these limitations, maximising the energy potential of these resources, increasing process efficiency, providing greater security of supply and reducing overall costs.
\end{abstract}

This work provides a practical introduction to the production of electricity from conventional Concentrating Solar Power (CSP) and biomass power plants, which is used as the basis to evaluate the technical and economic benefits associated with hybrid CSP-biomass energy systems. The paper initially analyses alternative configurations for a $10 \mathrm{MWe}$ hybrid CSP- biomass combustion power plant. The Solar Advisor Model (SAM) was used to determine the contribution of the solar field using quasi-steady generation conditions. The contribution of the biomass and gas boiler to the power plant was estimated considering the available radiation throughout the year. An economic assessment of a $10 \mathrm{MWe}$ power plant based on conventional CSP, biomass combustion and hybrid technology is calculated. The results show that investment costs for hybrid CSP- biomass power plants are higher than for conventional CSP and biomass combustion plants alone. However, owing to the shared use of some of the equipment, this value is significantly lower (24\% saving) than a simple addition of the investment costs associated with the two standard technologies. In contrast, effective operating hours and, therefore, overall energy generation, are significantly higher than in conventional CSP (2.77 times higher) and avoids the need for highly expensive heat storage system. Owing to the lower biomass requirements, hybrid plants may have larger capacities than standard biomass combustion plants, which implies higher energy efficiencies and a reduced risk associated with biomass supply. Universidad Politécnica de Madrid (UPM) is currently collaborating with a consortium of private companies in the development of a first commercial hybrid CSP-biomass combustion power plant that is expected to start operating in 2012.

KEYWORDS: hybrid technologies; renewable energy; Concentrating Solar Power (CSP); biomass; power stations.

\section{INTRODUCTION TO CSP AND BIOMASS COMBUSTION PLANTS}

Most governments in the world are adopting measures aimed at facilitating the deployment of renewable energy sources. Spain has often been cited as an example in this field owing to the efficiency of its regulatory framework in the development of alternative energy technologies (del Río, 
2008). As a result, this country has become the world leader in solar thermoelectric technology, with six commercial plants currently in operation and 27 plants under construction for a total capacity of 1,037 MWe (San Miguel et al., 2010).

In Concentrating Solar Power (CSP) plants, electricity is generated by heating a fluid (synthetic oil) to high temperatures (typically over $375^{\circ} \mathrm{C}$ ) using solar radiation that has been concentrated using mirrors or lenses. The hot fluid is used to produce superheated steam (370-375 ${ }^{\circ} \mathrm{C}, 90-100$ bar depending on the characteristics of the Rankine cycle) (Montes et al., 2009) that drives a Rankine cycle steam turbine connected to an electricity generator. Different technologies have been developed to concentrate the solar radiation, depending on the required fluid temperature, plant size and capacity. The most widely used are power towers and parabolic throughs (Wolff et al., 2008). A key drawback in CSP plants relates to the intermittence of its power generation, due to the day/night cycles and also the periods of reduced irradiation (winter, cloudy periods). To overcome this problem, research is being conducted to develop efficient heat storage systems (molten salts, concrete, latent heat) and other energy storage alternatives (pumped hydroelectricity, hydrogen, etc). However, these technologies have been reported to be expensive and/or not sufficiently proven (Palgrave, 2008).

In contrast, biomass combustion is a mature technology with a large number of power plants in operation worldwide. However, the energy efficiency of this technology is limited and the operating and investment costs are high, resulting in low financial returns (Caputo et al., 2005). Biomass power plants have been adapted to different fuels (agriculture and industrial by-products, energy crops), with plant capacities typically ranging between 2-50 MWe. The larger plants benefit from comparatively higher energy efficiencies (usually up to 22-23\%) but have to face the challenge of meeting a demand for large amounts of biomass, a resource characterised for its increasing scarcity, high cost and seasonality (López-González et al., 2007).

\section{TECHNOLOGY ASSESSMENT OF CSP AND BIOMASS COMBUSTION}

Both CSP and biomass combustion plants are based on the Rankine cycle where thermal energy is used to generate superheated steam and obtain electricity in a turbine-generator set. Below are described the main elements that make up conventional CSP and biomass power stations and the different specifications.

\subsection{CSP plants}

In Concentration Solar Power (CSP) plants, moving mirrors track the movement of the sun in order to concentrate the solar radiation onto the heating fluid. Different designs have been developed, the most common being parabolic troughs. As illustrated in Figure 1, the energy contained in the heat transfer fluid (HTF) is transferred to a water feed to generate superheated steam in a multiple stage heat exchange system. This steam is directed onto a turbine generator.

The most important elements in CSP plants are the following:

- The Solar collectors are made up of a supporting structure (to withstand elements), mirrors (where the solar beams are reflected and directed to the absorber tube), absorber tubes (containing the heat transfer fluid - HTF), and the driving systems (to track sun path). The solar system is usually backed up by a natural gas boiler that operates at different rates depending on the degree of solar irradiation.

- The heat recovery boiler is where heat from the HTF is used to generate superheated steam $\left(370-375^{\circ} \mathrm{C}, 90-100\right.$ bar). Most heat recovery boilers consist of several heat exchange stages, including an economizer, an evaporator and a superheater. Depending on the type of plant and cycle optimization, a reheater may be also included.

- Auxiliary equipment: Pumps used in CHP plants need to be specially designed to operate with HTF. Variable Frequency Drives (VFD) are used to control the pumping force that is exerted at every moment, in order to adjust HTF flows to the plant requirements. To keep production during cloudy weather and facilitate the operation and starting off of the solar field at low temperatures, natural gas boilers are used to ensure optimum temperature of the transfer fluid. 


\subsection{Biomass combustion plant}

Figure 2 illustrates the flow diagram of a conventional biomass combustion power plant. The main component in this system is the boiler, which is where biomass is burnt to generate superheated steam. Energy generated in the combustion process is used to heat the feed water (economizer), generate steam (evaporator) and superheat the steam to its final temperature and pressure (superheater). All the components regarding biomass storage and preparation area need to be considered in a technical and economic evaluation of a biomass power plant. However, for ease of discussion and reduce complexity, these will not be specified in this document.

\subsection{Common equipment}

The thermal nature of the energy employed in both CSP and biomass combustion power plants make these two processes compatible and complementary (Chasapis et al., 2008), as described below:

- Turbine-generator set, where thermal energy is transformed first into mechanical energy and finally into electricity by means of a power generator. Since the working fluid is the same in both technologies (superheated steam), a unique turbine-generator set may be shared by a hybrid solar-biomass system.

- Common elements in the Rankine cycle: including not only pipes, valves and control devices, but also the condenser, cooling towers and the deaerator.

- Common services: feed water, compressed air and gas supplies, electrical devices and infrastructures are necessary both in CSP and biomass combustion plants.

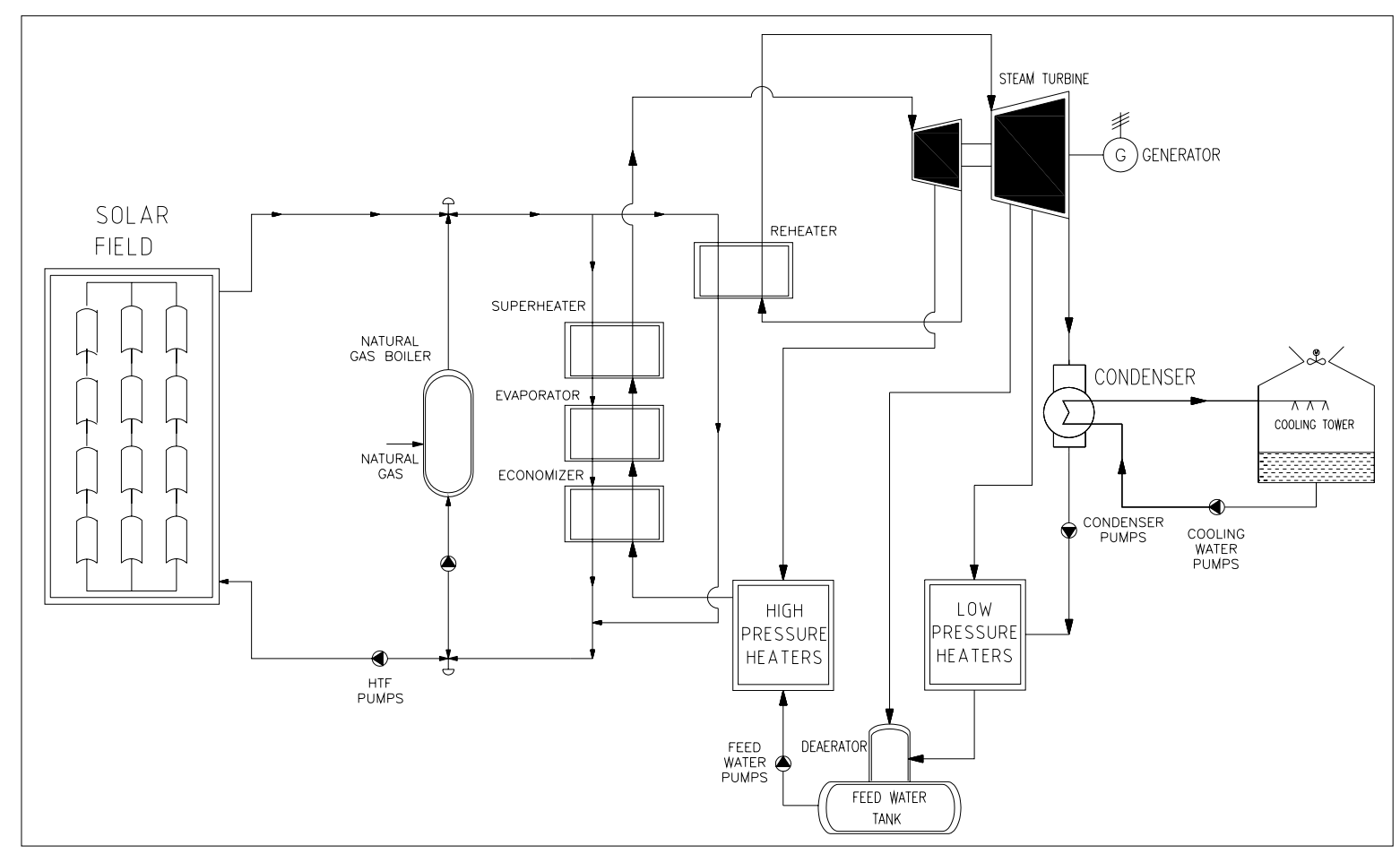

Figure 1. Basic process flow diagram of a CSP power plant

\section{ALTERNATIVE CONFIGURATIONS OF A CSP-BIOMASS HYBRID SYSTEM}

In CSP and biomass power plants, heat is produced as an intermediate source of energy that is driven to the turbine-generator set for the generation of electricity. This compatibility can be used to design a power plant that uses CSP during the day and biomass during periods of reduced irradiation (night, cloudy periods, transients). Hence, CSP- Biomass combustion hybrid technology relies on the effective integration of a solar collector into the water/steam cycle of a biomass power plant. 


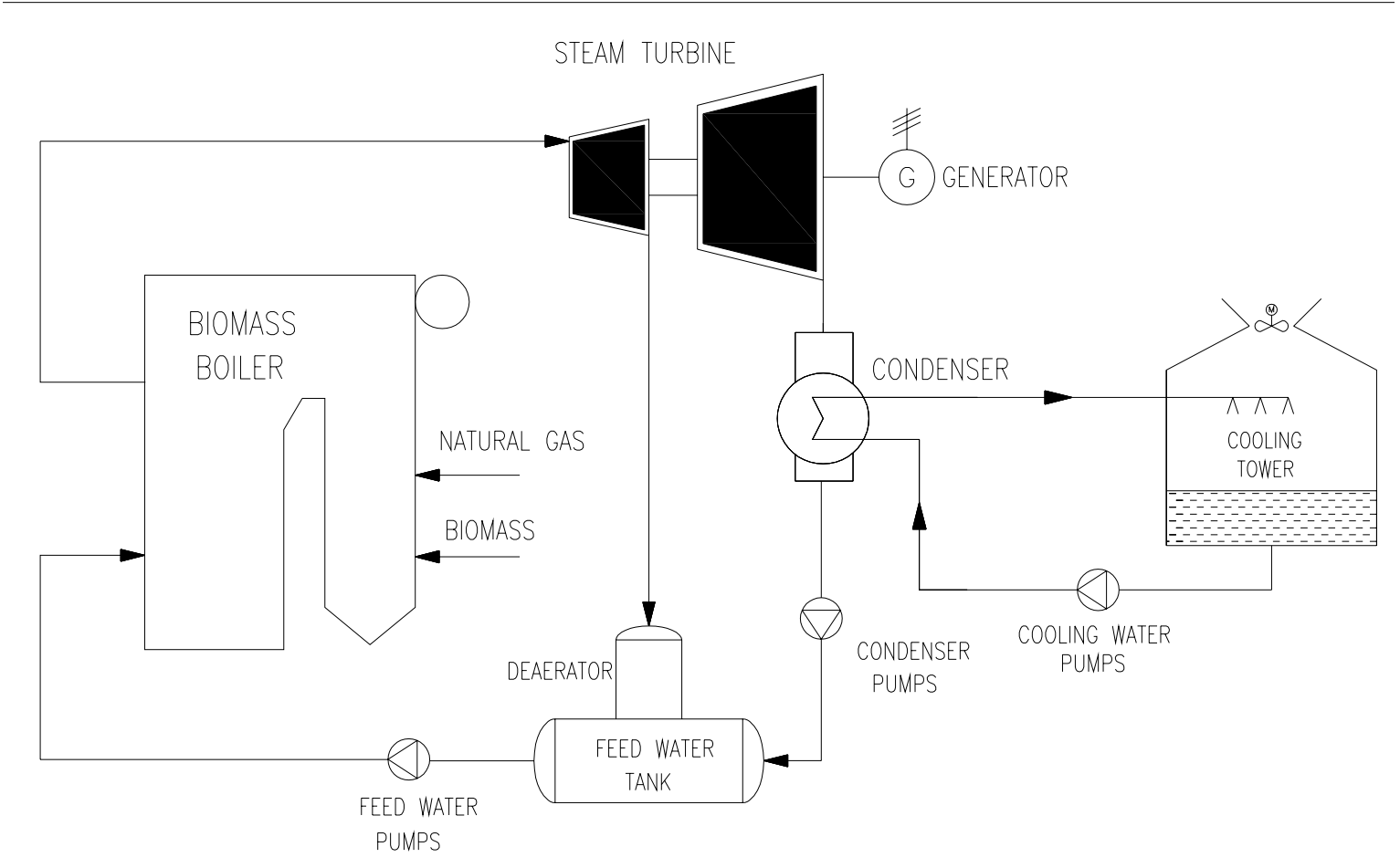

Figure 2. Basic process flow diagram of a biomass combustion power plant

As will be described below, the combination of these two technologies benefits from increased overall energy efficiency of the system, reduced investment per unit of power capacity (compared to CSP with molten salts heat storage), and longer operating hours (24 hours a day without the need for relevant heat storage) (Chasapis et al., 2008). The biomass and the solar thermal Rankine cycles may be interconnected using one of two configurations: substituting the backup natural gas boiler for a biomass boiler; or connecting the solar field and biomass boiler in parallel. These alternatives are discussed below.

\subsection{Substitution of the backup natural gas boiler for a biomass boiler}

In this configuration, shown in Figure 3, the biomass boiler is designed to heat the HTF coming from the solar field instead of water. As it happened with the original natural gas boiler, this kind of design requires the biomass boiler to have a very efficient dynamic response in order to adapt its working point to the variability of solar irradiation conditions. For this purpose, the biomass boiler usually includes a rapid response natural gas backup system.

\subsection{Connecting the solar field and biomass boiler in parallel}

In this case (Figure 4), both the solar and the biomass systems have the capacity to generate superheated steam. Both streams are connected together for increased energy generation. In order to maintain appropriate steam conditions, the volume of water fed through the biomass boiler is adjusted depending on the solar irradiation and the steam generated by the solar field. The biomass boiler operates at different capacities, depending on the solar contribution, to produce a constant electricity output. 


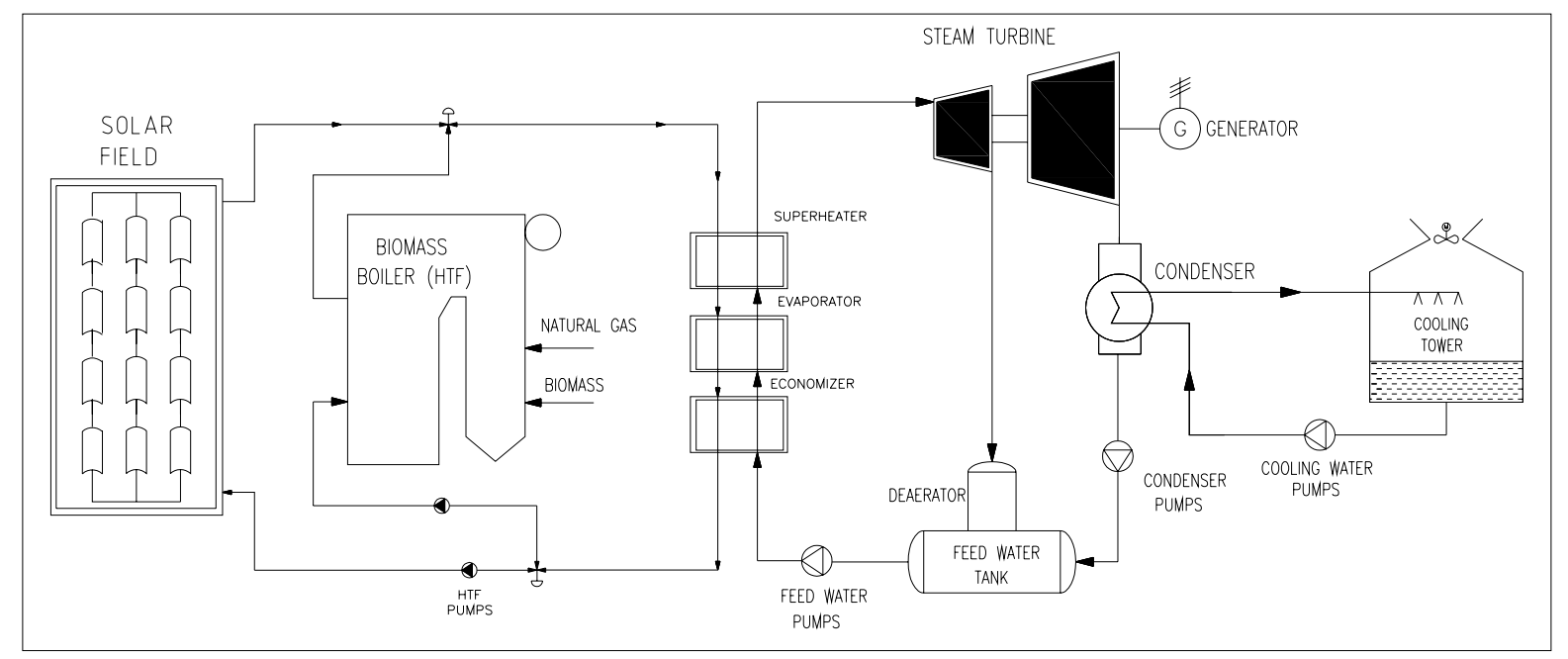

Figure 3. CSP-biomass hybrid configuration where the natural gas boiler has been substituted by a biomass boiler

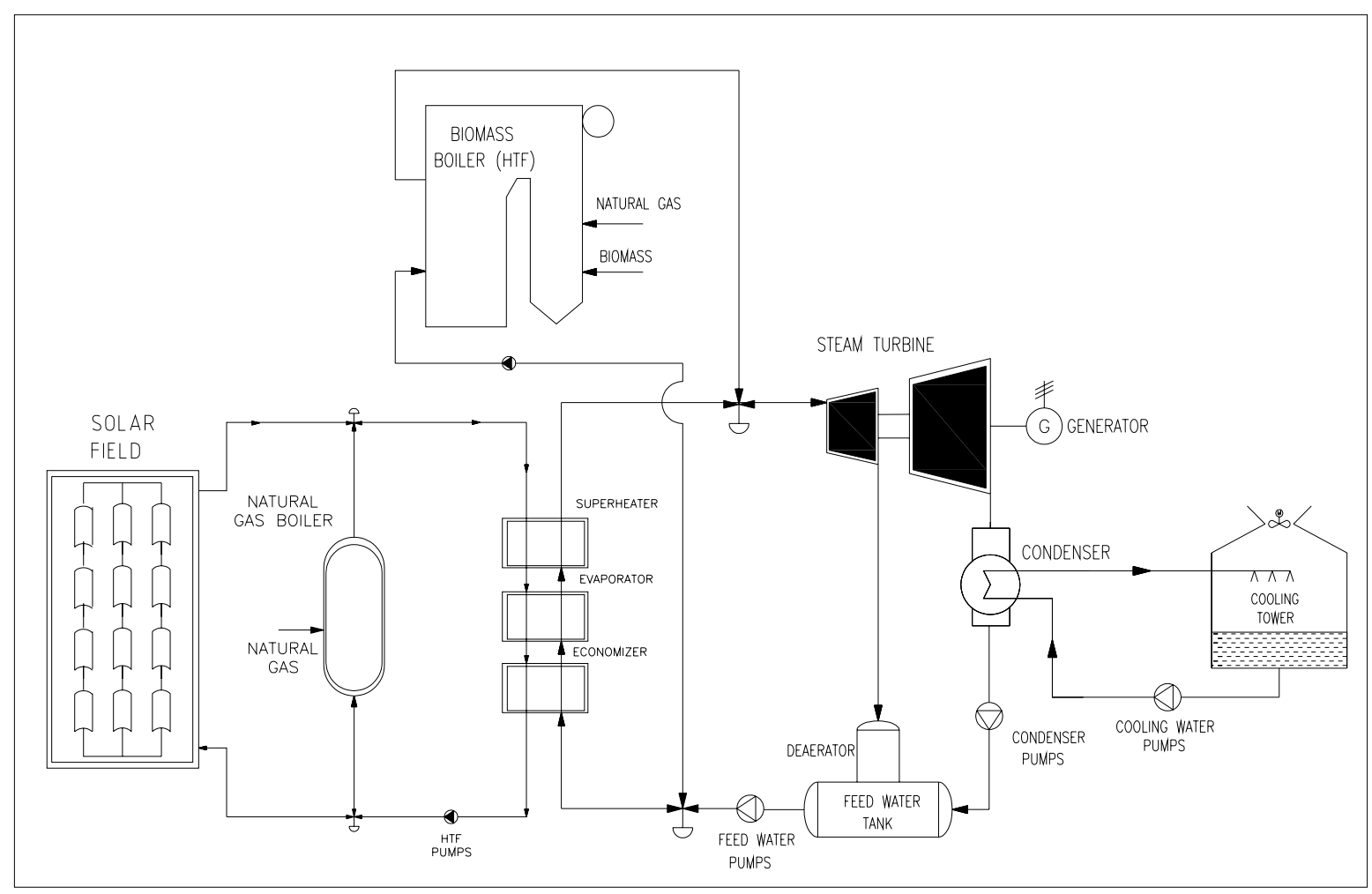

Figure 4. Solar-biomass hybrid configuration with CSP and biomass units set in parallel

\section{TECHNOLOGY ASSESSMENT OF CSP-BIOMASS HYBRID TECHNOLOGY}

The first parameter that needs to be considered in the design of the power plant is power capacity, as both the economics and the energy performance of the plant are sensitive to scale factors. In general terms, larger plants benefit from higher energy efficiencies and take advantage of increasing economies of scale. However, large plants encounter difficulties to ensure a sustainable and stable supply of biomass feedstock. For the purpose of this analysis, a $10 \mathrm{MW}$ power plant has been selected as an optimum balance between performance and biomass supply. Although optimum working pressure may be in the order of 90-100 bar for a 50MW power plant, 63 bar were chosen for this $10 \mathrm{MW}$ power plant to minimize expenses and technical difficulties. 
The plant configuration based on the substitution of the back-up natural gas boiler for a biomass boiler (see Figure 4) benefits from easier operation control and also from reduced construction costs, owing to the fact that no natural gas boiler is required. On the other hand, the main disadvantage for this option is the lower performance of the biomass cycle, due to the need to use heat exchangers for the HTF fluid. The boiler substitution configuration will be analysed in this work. From a conceptual standpoint, the key operating conditions of this hybrid plant would involve:

- Whenever possible, the power generation should be based on the CSP cycle, since the fuel (solar irradiation) is free and the operating costs are minimised.

- Natural gas will be used in the biomass boiler to provide primary energy during short transients, such as cloudy weather or transitions between biomass and CSP cycles.

- Biomass combustion will be used during longer periods when solar resource is unavailable, as for example during nights and winter days.

\subsection{Modelling and methodology}

To estimate electric production and simulate the conditions given above, a simplified model has been developed. Thermal production in the solar field has been simulated using the Solar Advisor Model (SAM) from NREL (2008). A quasi-steady model was used to calculate solar field production on an hourly basis. Depending on the thermal production values produced for the solar field, the power required from the natural gas heaters and the biomass boiler were calculated for a steady generation in the Rankine cycle of $10 \mathrm{MWe}$. Differences of production along the year depend on parasitics loads and threshold values for minimum operation of the biomass boiler and auxiliary heaters, which are stated at $25 \%$ of nominal operation.

Dynamic responses of the different primary energy resources are not considered in this analysis. Also, full-load operation is considered for all the hours of the year, and performance losses due to partial-load operation should be included in future simulations.

Table 1 describes the system inputs, as considered for the simulation the model.

Table 1. Input values for the simulation of the solar-biomass hybrid plant

\begin{tabular}{|c|c|}
\hline Metheorological data: & TMY artificially generated \\
\hline DNI: & $2,000 \mathrm{kWh} \mathrm{m}^{-2 \star}$ year \\
\hline \multicolumn{2}{|l|}{ Solar Field: } \\
\hline Number of loops: & 30 \\
\hline Aperture length of solar collectors: & $5.75 \mathrm{~m}$ \\
\hline Loop length: & $600.00 \mathrm{~m}$ \\
\hline Collector type: & ET-150 \\
\hline Solar Receiver: & Schott PTR70 \\
\hline \multicolumn{2}{|l|}{ Auxiliary gas heaters: } \\
\hline Performance: & $88 \%$ \\
\hline LHV (natural gas): & $10,500 \mathrm{kcal} \mathrm{kg}^{-1}$ \\
\hline \multicolumn{2}{|l|}{ Biomass boilers: } \\
\hline Performance: & $88 \%$ \\
\hline LHV (biomass): & $2,800 \mathrm{kcal} \mathrm{kg}^{-1}$ \\
\hline \multicolumn{2}{|l|}{ Heat exchangers: } \\
\hline Performance: & $100 \%$ \\
\hline Parasitic loads: & Defined hourly by SAM Model \\
\hline \multicolumn{2}{|l|}{ Turbine Steam input: } \\
\hline Temperature: & $375^{\circ} \mathrm{C}$ \\
\hline Pressure: & $63 \mathrm{bar}$ \\
\hline Flow at nominal point (100\%): & 44.52 Ton $\mathrm{h}^{-1}$ \\
\hline
\end{tabular}




\subsubsection{Solar field thermal production}

An hourly calculation has been done for a model year with a DNI $=2000 \mathrm{kWh} \mathrm{m}^{-2}$. SAM can export a file with the hour production of the solar field. To close the circuit and check the heat and mass balances in the model, the volumetric flow is determined using the following expression:

$\dot{V}_{H T F}=\frac{\dot{Q}_{S F} * A_{S C A} * L_{l o o g} * N_{\text {loog }}}{\Delta h_{H T F} * \rho\left(T_{l m}\right)}$

- $\dot{V}_{H T F}:$ HTF volumetric flow in the solar field.

- $\bar{Q}_{S F}$ : Heat collected in the solar field, based on hourly data. It has been calculated using SAM program from NREL, and using the same parameters as a conventional solar thermal power plant.

- $A_{S S A}$ : Aperture length of the solar collector. This value is $5,75 \mathrm{~m}$.

- $L_{l o g}$ : Loop length. Value: $600 \mathrm{~m}$.

- $\quad N_{\text {lnngr }}:$ Number of loops. This value needs to be optimized depending on the ratio production/cost. For this model, 30 loops have been considered.

- $\Delta h_{H T F}$ : HTF Increase of enthalpy.

- $\quad \rho\left(T_{l m}\right)$ : HTF density at the mean logarithmic temperature in the Solar Field.

The configuration of the solar field is divided into several loops, which are arrays of solar collector units. Technical details can be seen in (Montes et al., 2009) and (Richter et al., 2009). Loop length is the optimal length needed to increase the temperature of the oil from $292^{\circ} \mathrm{C}$ to $392^{\circ} \mathrm{C}$ in a loop.

Number of loops has been oversized in order to maximize solar field production and to compensate the decrease of the Rankine performance cycle.

\subsubsection{Natural gas heaters and biomass boilers}

To simplify the modelling of the natural gas boilers, it has been considered that they will only be used during summer, where the solar field produces most of the output power, and the needs of auxiliary heaters to keep working temperatures are minimum. Biomass boilers are used in the same way as natural gas heaters, but since the dynamic response is slower, they will be used during periods of reduced solar irradiation.

The thermal energy produced in these systems is calculated as the difference between the solar field production and the full-load needs, and set to meet the Spanish legislation requirements. The fuel required to obtain the energy calculated with the previous consideration can be calculated assuming a performance of $88 \%$ for both systems at the full-load points. The needs for auxiliary fuel are given by the following expression:

$\dot{m}_{f}=\frac{\hat{Q}_{f l}-\hat{Q}_{s f}}{\eta_{r} \cdot L H V_{f}}$

where:

- $\quad \bar{Q}_{f l^{i}}$ Heat needed for full/load production.

- $\bar{Q}_{s f}$ : Heat collected in the solar field.

- $\quad \eta_{r}$ : Performance of auxiliary heating system. Value set to $88 \%$ for natural gas heaters and biomass boiler.

- $\quad L H V_{\digamma}$ : Lower heating value of the fuel. The value for biomass is $2800 \mathrm{kcal} \mathrm{kg}^{-1}$ and for natural gas is $10500 \mathrm{kcal} \mathrm{kg}^{-1}$.

This value is needed to estimate the fuel consumption needed to heat the HTF that cannot be heated in the Solar Field. 


\subsubsection{Rankine cycle: electric output}

All performance considered is based on steam balances, and the following formula is applied (Kiameh, 2003):

$$
\eta_{R}=\frac{E p}{m_{g} *\left(h_{s}-h_{g}\right)}
$$

- $E_{P}$ : Electrical power produced. The calculated value resulted in $10296 \mathrm{~kW}$.

- $\dot{m}_{g}$ : Steam flow in the heat recovery boiler.

- $h_{g}$ : Enthalpy of the steam at the heat recovery boiler outlet.

- $h_{\mathrm{f}}$ : Enthalpy of the steam at the heat recovery boiler inlet.

- $\eta_{R}$ : Rankine cycle performance. The calculated value for the nominal point (100\% load) is $30,6 \%$.

The results obtained from these calculations are given in Figure 5 and Table 2.

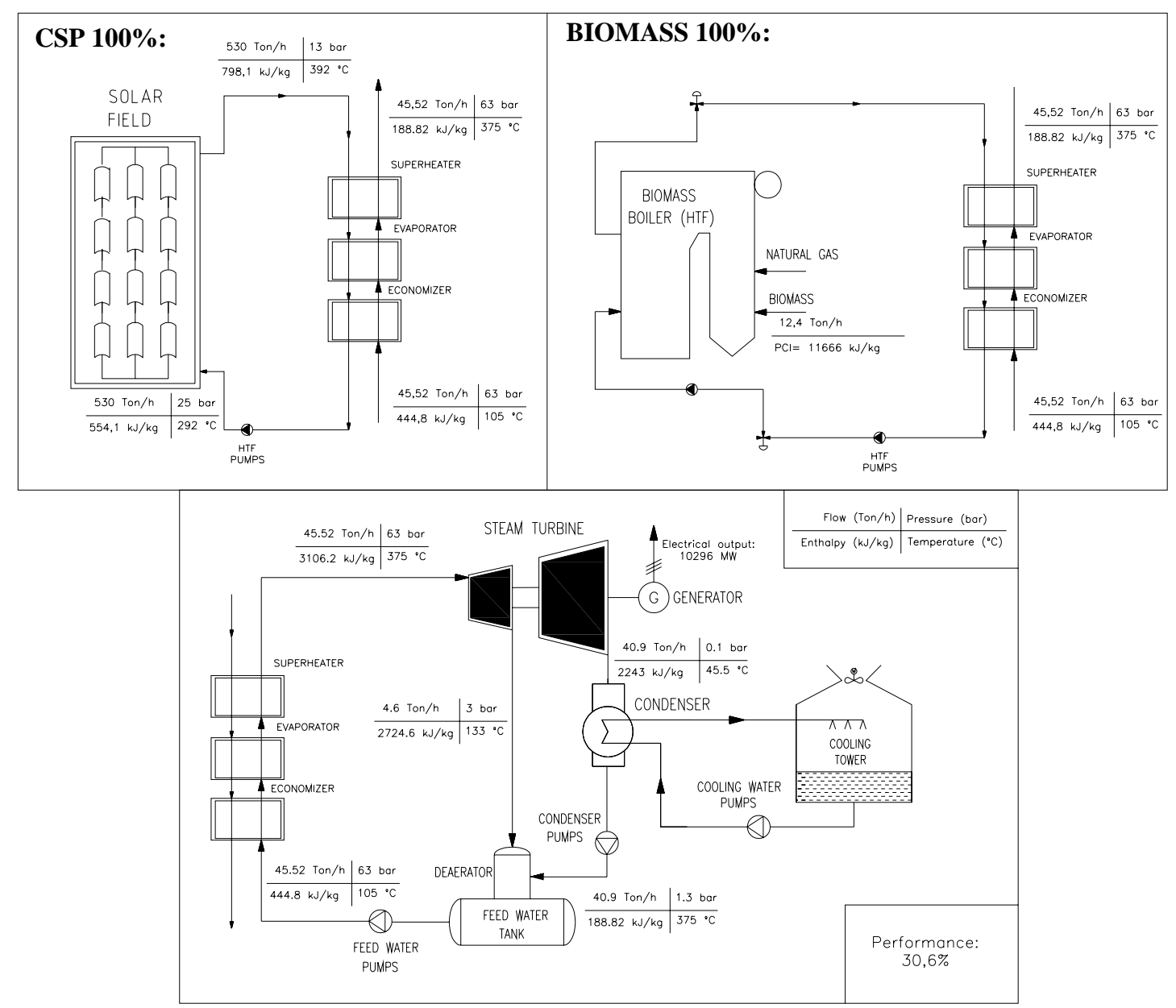

Figure 5. Detailed process flow diagram for CSP energy production, Biomass energy production and Rankine cycle of a $10 \mathrm{MW}$ hybrid CSP-biomass combustion plant

The Rankine cycle conditions for the CSP, biomass and hybrid configurations are illustrated in Figure 5 and the estimated monthly electrical generation is shown in Table 1. Based on standard irradiation conditions, the results in Table 1 show a maximum CSP capacity during the summer period ( $3218 \mathrm{kWh}$ in July), during which time the biomass unit is completely stopped. In contrast, the biomass reaches over $91 \%$ of the energy contribution during the winter months. The overall energy output would remain relatively stable throughout the year at between 5500-7000 kWh. 
Table 2. Estimated monthly electrical production (kWh) based on biomass combustion, CSP, and natural gas for a $10 \mathrm{MW}$ hybrid plant

\begin{tabular}{|l|r|r|r|r|}
\cline { 2 - 5 } \multicolumn{1}{c|}{} & CSP & Biomass & Natural Gas & Total \\
\hline January & 434 & 5811 & 0 & 6245 \\
February & 711 & 5061 & 0 & 5773 \\
March & 1963 & 4806 & 0 & 6769 \\
April & 1942 & 4629 & 0 & 6571 \\
May & 2604 & 4417 & 0 & 7021 \\
June & 3064 & 1750 & 1485 & 6299 \\
July & 3218 & 0 & 2415 & 5634 \\
August & 2927 & 0 & 2558 & 5485 \\
September & 2120 & 4514 & 0 & 6634 \\
October & 1109 & 5409 & 0 & 6519 \\
November & 391 & 5630 & 0 & 6021 \\
December & 95 & 2869 & 0 & 2964 \\
\hline ANNUAL & 20579 & 44897 & 6459 & 71934 \\
\hline
\end{tabular}

\section{ECONOMIC ASSESSMENT}

This economic assessment is based on reference values provided in the Spanish Plan de Energías Renovables (Renewable Energy Plan 2005-2010) (MITYC, 2005). The investment costs have been calculated for a 10 MWe power plant based on CSP, biomass combustion and hybrid technology.

Table 3. Initial investment costs of the different technologies for a $10 \mathrm{MW}$ plant

\begin{tabular}{|c|c|c|c|c|c|c|c|c|}
\hline \multicolumn{3}{|c|}{ CSP Plants } & \multicolumn{3}{|c|}{ Biomass combustion plants } & \multicolumn{3}{|c|}{ Hybrid biomass-CSP plants } \\
\hline & & & $\begin{array}{l}\text { Biomass treatment } \\
\text { plant }\end{array}$ & & & $\begin{array}{l}\text { Biomass treatment } \\
\text { plant }\end{array}$ & & $€ / M W$ \\
\hline & & & Biomass boiler & 800 & $€ / M W$ & Biomass boiler & 800 & $€ / M W$ \\
\hline Solar Field & 2300 & $€ / \mathrm{kW}$ & & & & Solar Field & 2300 & $€ / \mathrm{kW}$ \\
\hline $\begin{array}{l}\text { Heat recovery } \\
\text { boiler }\end{array}$ & 200 & $€ / \mathrm{kW}$ & & & & Heat recovery boiler & 200 & $€ / \mathrm{kW}$ \\
\hline $\begin{array}{l}\text { Heat transfer } \\
\text { system }\end{array}$ & 200 & $€ / \mathrm{kW}$ & & & & $\begin{array}{l}\text { Heat transfer } \\
\text { system }\end{array}$ & 200 & $€ / \mathrm{kW}$ \\
\hline Turbogenerator set & 750 & $€ / \mathrm{kW}$ & Turbogenerator set & 750 & $€ / \mathrm{kW}$ & Turbogenerator set & 750 & $€ / \mathrm{kW}$ \\
\hline Heat storage & 300 & $€ / \mathrm{kW}$ & & & & Heat st & 300 & $€ / \mathrm{kW}$ \\
\hline BOP & 450 & $€ / \mathrm{kW}$ & BOP & 450 & $€ / \mathrm{kW}$ & BOP & 450 & $€ / \mathrm{kW}$ \\
\hline Evacuation line & 50 & $€ / k W$ & Evacuation line & 50 & $€ / \mathrm{kW}$ & Evacue & 50 & $€ / \mathrm{kW}$ \\
\hline Civil Works & 400 & $€ / \mathrm{kW}$ & Civil Works & 400 & $€ / \mathrm{kW}$ & Civil Works & 400 & $€ / \mathrm{kW}$ \\
\hline Assemb.+Commiss. & 350 & $€ / \mathrm{kW}$ & Assemb.+Commiss. & 350 & $€ / \mathrm{kW}$ & Assemb.+Commiss. & 350 & $€ / \mathrm{kW}$ \\
\hline TOTAL & 5.000 & $€ / \mathrm{kW}$ & TOTAL & 3200 & $€ / \mathrm{kW}$ & TOTAL & 6200 & $€ / \mathrm{kW}$ \\
\hline
\end{tabular}

The results in Table 3 show that investment costs per unit power installed are higher for the hybrid plant $(6200 € / \mathrm{kW})$ than for the CSP $(5000 € / \mathrm{kW})$ or biomass $(3200 € / \mathrm{kW})$ technologies. However, the synergies discussed above lead to a $24 \%$ saving from the simple addition of the two standard technologies.

Table 4 illustrates that biomass combustion plants have the highest operating costs, owing primarily to the cost of the biomass fuel and labour requirements. In contrast, operating costs in CSP plants are one fifth of biomass combustion plants, due to the free nature of the solar resource. However, equivalent hours and, consequently, energy generation values are significantly lower in CSP plants.

Considering the Levelised Cost of Electricity (LCOE) values calculated for each plant design, it may be concluded that biomass power plants provide the cheapest alternative, with $116,05 € / \mathrm{MWh}$. 
However, this alternative relies on the sustainable supply of large amounts (estimated $75000 \mathrm{t}$ year ${ }^{1}$ ) of a biomass whose price and availability is not always secure. Biomass market prices have been growing in the last years, and it is expected that this trend will continue in the future. LCOE values for the hybrid plant $(153,56 € / M W h)$ have been calculated to be $32 \%$ higher than the biomass power plant but $36 \%$ lower than the conventional CSP.

Table 4. Comparative economic and performance assessment of three $10 \mathrm{MWe}$ power plants based on CSP, biomass combustion and hybrid technologies

\begin{tabular}{|l|l|l|l|l|l|}
\hline \multicolumn{2}{|c|}{ CSP Plants } & \multicolumn{2}{c|}{ Biomass combustion plants } & \multicolumn{2}{c|}{ Hybrid biomass-CSP plants } \\
\hline $\begin{array}{l}\text { Investment } \\
\text { costs }\end{array}$ & $50000000 €$ & $\begin{array}{l}\text { Investment } \\
\text { costs }\end{array}$ & $32000000 €$ & $\begin{array}{l}\text { Investment } \\
\text { costs }\end{array}$ & $62000000 €$ \\
\hline Operating costs & $1102400 €$ & Operating costs & $5329425 €$ & Operating costs & $4641310 €$ \\
\hline $\begin{array}{l}\text { Equivalent } \\
\text { hours } \\
\text { Production }\end{array}$ & $\begin{array}{l}2600 \mathrm{ha} \\
26000 \mathrm{MWh}\end{array}$ & $\begin{array}{l}\text { Equivalent } \\
\text { hours } \\
\text { Production }\end{array}$ & $\begin{array}{l}7500 \mathrm{~h} \\
75000 \mathrm{MWh}\end{array}$ & $\begin{array}{l}\text { Equivalent } \\
\text { hours } \\
\text { Production }\end{array}$ & $\begin{array}{l}7193.4 \mathrm{~h} \\
71934 \mathrm{MWh}\end{array}$ \\
\hline LCOE: & $\begin{array}{l}238.69 \\
€ / \mathrm{MWh}\end{array}$ & LCOE: & $\begin{array}{l}116.05 \\
€ / \mathrm{MWh}\end{array}$ & $\begin{array}{l}153.56 \\
\text { LCOE: }\end{array}$ & $\mathrm{MWh}$ \\
\hline
\end{tabular}

LCOE = Levelised Cost of Electricity

\section{CONCLUSIONS}

A technical and economic assessment of Concentrating Solar Power (CSP) and biomass combustion evidences the complementarity of these two technologies in the generation of electricity. Solar energy plants benefit from the use of a freely available source of energy but suffer from the intermittency of the day/night cycles and also from periods of reduced irradiation (winter, cloudy days). In contrast, biomass power plants are comparatively less expensive to build but have to confront the higher cost and risks associated with the continuous supply of large amounts of a seasonal and increasingly expensive biomass fuel.

This paper provides a preliminary technical and economic analysis of hybrid CSP-biomass combustion plants, as an alternative to conventional CSP and biomass power technology. The results show that investment costs for hybrid CSP- biomass power plants are higher than for conventional CSP and biomass combustion plants alone. However, owing to the shared use of some of the equipment, this value is significantly lower ( $24 \%$ saving) than a simple addition of the investment costs associated with the two standard technologies. In contrast, effective operating hours and, therefore, overall energy generation, have been calculated to be is significantly higher than in conventional CSP (2.77 times higher). Hybridation of biomass also avoids the need for highly expensive heat storage system in conventional CSP. The main advantages in comparison with a biomass plant are: the increase of renewable energy which may be produced in an area and the fact that around $1 / 3$ of total output relays on a free reliable source of primary energy, thus reducing the risk associated with biomass supply.

Finally, the use of common equipment and the combined performance of the two technologies leads to a lower Levelised Cost of Electricity (LCOE) in hybrid plants than the simple addition of the weighted LCOE values obtained from independent biomass and CSP output contributions.

Two critical factors need to be further investigated in order to have a better understanding of the efficiency of hybrid power plants: firstly, the dynamics of the combined system need to be understood and adjusted in order to optimise the functioning of the hybrid plant; secondly, losses derived from the partial-load operation of individual system units need to be determined in order to calculate real energy efficiencies.

\section{ACKNOWLEDGEMENTS}

The authors wish to thank Ministerio de Ciencia e Innovación (MICINN) (Spanish Ministry of Science and Innovation) for financial support under Plan Nacional de Investigación, Desarrollo e Innovación Tecnológica 2008-2011 (INNPACTO reference IPT-440000-2010-004). 


\section{REFERENCES}

Caputo A.C., Palumbo M., Pelagagge P.M., Scacchia F. (2005), Economics of biomass energy utilization in combustion and gasification plants: effects of logistic variables, Biomass and Bioenergy, 28(1), 3551.

Chasapis D., Drosou V., Papamechael I., Aidonis A., Blanchard R. (2008), Monitoring and operational results of a hybrid solar-biomass heating system, Renewable Energy, 33(8), 1759-1767

Kiameh P. (2003). Power generation handbook: selection, applications, operation, and maintenance. New York: McGraw-Hill, cop. 2003.

López-González L.M., Sala J.M., Mínguez-Tabarés J.L., López-Ochoa L.M. (2007), Contribution of renewable energy sources to electricity production in the autonomous community of Navarre (Spain): A review, Renewable and Sustainable Energy Reviews, 11(8), 1776-1793

MITYC (2005), Ministerio de Industria, Turismo y Comercio (MITYC). Plan de Energías Renovables 2005-2010, Servicio de Publicaciones del Ministerio de Industria, Turismo y Comercio (MITYC), Madrid, 2005

Montes M.J., Abánades A., Martínez-Val J.M., Valdés M. (2009), Solar multiple optimization for a solaronly thermal power plant, using oil as heat transfer fluid in the parabolic trough collectors, Solar Energy 83, 2165-2176.

NREL (2008), Solar Advisor Model 2.5.0.2. Available on line at: https://www.nrel.gov/analysis/sam/.

Palgrave R. (2008) Innovation in CSP, Renewable Energy Focus, 9(6), 44-49

Del Río P. (2008) Ten years of renewable electricity policies in Spain: An analysis of successive feed-in tariff reforms. Energy Policy, 36, 2917- 2929

Richter C., Blanco J., Heller P., Mehos M., Meier A., Meyer (R.2010), SolarPACES Annual Report 2009. On line at: http://www.solarpaces.org/Library/AnnualReports/documents/AnnualReport2009Final web.pdf

San Miguel G., del Río P., Hernández F. (2010), An update of Spanish renewable energy policy and achievements in a low carbon context. Journal of Sustainable and Renewable, 2(3) 1-17

Wolff G., Gallego B., Tisdale R., Hopwood D. (2008), CSP concentrates the mind, Renewable Energy Focus, 9(1), 42-47 